\title{
Scientists in the Bond film franchise
}

Claire Hines, Solent University

\begin{abstract}
The James Bond film franchise (1962-ongoing) has always relied on science and technology for topicality and spectacle. Over the years, the scientist figure has also made regular appearances in the Bond films, most often within the confines of some of the established character types and functions defined by the formula aspects of the series - the villain, the Bond girl and the Quatermaster, better known as Q. This article uses Bond scholarship to consider key examples of each of these depictions of the scientist in relation to the heroic masculinity of James Bond, and in the broader context of research examining images of scientists in popular fiction. In so doing the article contributes to ongoing debates about the representational politics of Bond and scientist stereotypes in popular culture.
\end{abstract}

\section{Keywords}

James Bond

Bond girl

Quatermaster

scientist stereotypes

Bond films

mad scientist 
The James Bond film franchise began with the release of $\operatorname{Dr}$ No (Young 1962), a film of many notable firsts for the long-running and highly formulaic series. These important firsts include the introduction of Sean Connery as James Bond, the introduction of the criminal organization SPECTRE and the first major Bond villain, the first of the Bond girls and a number of key recurring characters. Even though some changes were made to the novel written by Ian Fleming and published in 1958, the film nevertheless follows the same storyline: Bond is sent by the British Secret Service to Jamaica, where he uncovers an evil plot headed by a scientific mastermind. As the first of the Bond films, it is particularly significant that $\mathrm{Dr} N$ o has a scientist as the very first on-screen Bond villain. Played by Joseph Wiseman, Dr No was based on the literary character from Fleming's novel, and clearly followed in the tradition of the mad scientist, but also became the prototype for the many Bond villains that followed in the film series (Chapman 2007: 66). According to the stories that circulate about the preparation of $\mathrm{Dr}$ No, however, this was almost not the case. In his autobiography Bond producer Albert Broccoli recalls that he and Harry Saltzman rejected an early draft of the screenplay in which the screenwriters had departed from the novel and made the villain a monkey (Broccoli and Zec 1998: 158). Broccoli was adamant that the script needed to be rewritten and that Fleming's Bond villain should be restored to the screenplay (Broccoli and Zec 1998: 158). The idea that the book might have been adapted for the screen without the main villain who functions in opposition to Bond is now unthinkable, and in $\operatorname{Dr}$ No the antagonist's depiction as a scientist is essential to his characterization.

Dr No also established the prototype for the Bond girl, created as James Bond's love interest (Funnell 2008; Funnell 2018). Ursula Andress' iconic appearance in a white bikini emerging from the sea as Honey Ryder has been much discussed, especially for the way she is introduced on-screen as an erotic object, and a source of pleasure for the male gaze (Bennett and Woollacott 1987: 193-94; Chapman 2007: 66). However, less often discussed is that 
Honey Ryder is the only daughter of a widowed marine biologist. During the famous beach scene she tells Bond that she has lived all over the world, and rather than a conventional education she has learnt from an encyclopaedia (she says she is up to ' $\mathrm{T}$ '). This unconventional upbringing and knowledge of science without a formal education or any qualifications means that Honey Ryder can be understood as a clichéd type of the female scientist on-screen that film sociologist Eva Flicker characterizes as 'The daughter or assistant' (2003: 314, 2008: 24849). I will return to consider the Bond girl in the wider context of this and other research on the image of women scientists in mainstream film later on in this article. For now it is worth noting that Honey Ryder's presentation as innocent and childlike and her sexualization conforms to dominant stereotypes of the woman scientist that also appear in subsequent Bond films.

The third scientist type in $\operatorname{Dr}$ No is that of Q. However, in the first two Bond films this recurring character is referred to as Major Boothroyd and admittedly initially does little more than function as an equipment officer, recreating a scene from the novel where he replaces James Bond's Beretta with his signature Walther PPK gun. In From Russia with Love (Young 1963) Desmond Llewellyn takes over from Peter Burton in the role and this time the character introduces Bond to his new Secret Service issue briefcase, complete with a number of concealed gadgets. By Goldfinger (Hamilton 1964) he is credited as Q. It is the third Bond film that shows him in his workshop 'Q branch' when he presents Bond with a high-tech gadgetladen Aston Martin DB5. As described on the official James Bond website 007.com, '[Llewellyn's] Q is so much more than the Quartermaster his initial stands for. An endlessly inventive scientific genius, he runs a department within British Intelligence that stands at the forefront of technological innovation and often lifesaving ingenuity' (2017). Llewellyn stayed in the role of Q until The World is not Enough (Apted 1999) and appeared in seventeen Bond films. The character of Q did not appear in Casino Royale (Campbell, 2006) or Quantum of 
Solace (Forster, 2008), but returned in Skyfall (Mendes, 2012) and Spectre (Mendes, 2015), portrayed by Ben Wishaw. Although the two interpretations of the character differ in some important respects that will be discussed, Wishaw's new version of Q remains a scientistinventor.

The aim of this article is to examine these three different types of scientist character in the Bond film franchise: the villain, the Bond girl and the Quatermaster. I will identify that over the years, from $\mathrm{Dr} N o$ to the 24th instalment in the franchise Spectre, the scientist figure has made regular appearances within these recognized character types. As other scholars have discussed, these character types have each been defined by the formula aspects of the series, and in relation to Bond's heroic masculinity (Bennett and Woollacott 1987; Lindner 2009; Chapman 2007). Most notably, in the late 1980s Tony Bennett and Janet Woollacott's pioneering cultural studies analysis of the Bond phenomenon labelled James Bond a popular hero and a 'mobile signifier' (1987: 42). Given the popular fascination with James Bond for over 50 years and the influence that Bond has on popular culture, the Bond films have now been taken seriously by scholars for some time, and it is widely acknowledged that the world of Bond has considerable historical, political and cultural significance that extends far beyond the cinema (Bennett and Woollacott 1987; Weiner et al. 2011). This article contributes to the growing field of Bond scholarship, and also draws on studies examining the representation of scientists in fiction. In her wide-ranging book-length survey of fictional scientists, Roslynn D. Haynes $(1994 ; 2017)$ identifies a number of manifestations of the scientist figure, and shows how these images can be understood to construct and reflect their social and cultural worlds. Haynes notes that 'Studying the evolution of representations of scientists in Western literature, and more recently in film, allows us to see how clusters of these fictional images have coalesced to produce archetypes that have acquired cumulative, even mythological, importance' (2017: 4). As such, popular representations of scientists have similarly attracted academic attention 
for the ways that they might be categorized and understood in the contexts of their time. This article brings these areas of scholarship together to go beyond the signifying function of James Bond in order to consider the ways that the Bond films might reflect and shape our understanding of the scientist. I will furthermore contend that the recurring character of Q in particular has undergone a transformation that sheds further light on both the Bond films and the image of scientists in popular culture. In the Bond franchise Q does not remain unchanged from film to film, and when the character returns in the Daniel Craig era there (re)forms a complementary relationship between the (old) field agent and the (new) scientist.

\section{The mad scientist Bond villain}

Both the Bond villain and the mad scientist are might at first thought independently summon up images of a dangerous individual, furiously working on some secret plan to either destroy or takeover the world. In studies of fiction and popular culture the mad scientist has been identified as an enduring and dominant negative stereotype (Haynes 2003: 244; Hark 2004: 301; Pansegrau 2008: 261). Characters such as Dr Rotwang in Metropolis (Lang 1927), the Universal film adaptation of Mary Shelly's Frankenstein (Whale 1931) and the villain of $\mathrm{Dr}$ Strangelove (Kubrick 1964) illustrate how the mad scientist has been used by filmmakers to represent the prevailing concerns of the era, from the consequences of modernity in the $1920 \mathrm{~s}$ to atomic research in the 1950s and the 1960s (Frayling 2005: 9-47). Since $\operatorname{Dr}$ No, the fear that science and technology might make its way into the wrong hands has been central to the Bond films. Real-life events at the time of the film's release helped to make the screen version of $\mathrm{Dr}$ No topical as the villain's plan to sabotage the US missile programme reflected reports that American rocket testing had recently had problems with rockets 'going dangerously astray' (Dodds 2007: 79). Dr No's need to dominate and control means that he clearly fits in to the 
evil world ruler mad scientist subtype, who Petra Pansegrau observes 'is capable of being polite and civilised in order to conceal himself when it serves his purpose' (2008: 263). With $\mathrm{Dr} N o$ begins the on-screen tradition of the villain inviting James Bond to join him and socialize rather than simply killing Bond immediately. Over dinner, Dr No arrogantly explains his plans and casually invites Bond to become a member of SPECTRE, but scornfully labels Bond 'a stupid policeman' when he refuses. Pansegrau contends that films depicting this version of the mad scientist normally have a happy ending: 'In the end the good guy (usually not a scientist) wins and the evil utopian ruler must die' (2008: 263). This is indeed the case in $\operatorname{Dr}$ No when James Bond successfully manages to put a stop to the villain's plan to sabotage a US rocket by overloading a reactor, and during a fight Dr No falls into a pool of boiling hot, radioactive water when his mechanical hands are unable to grip the ladder well enough to pull himself out of the coolant pool.

When Christopher Frayling puts Dr No alongside the characters of Dr Rotwang from Metropolis and Dr Strangelove he points out that the mad scientist is often depicted with a physical disability (2005: 29). Like Rotwang's metal hand and Strangelove's gloved hand, Dr No's black metallic hands visibly signal his uncanny otherness (Frayling 2005: 26). In Dr No, the villain's prosthetic hands are said to be a result of his radiation experiments and act as an external symbol of his negative impulses such as sadism and moral corruption. Physical disability and disfigurement are often used by Fleming in his writing to signify the villain's evil (Eco 2009: 38), and even the most recent Bond films still employ the use of physical difference in this way. In Casino Royale LeChiffre has a malformed tear duct that causes him to cry blood, and in Skyfall the former British secret agent turned vengeful cybervillain Raoul Silva reveals his disfigured face otherwise disguised by a dental prosthesis. In contrast to these villains, James Bond is presented as physically and morally superior, and in the Craig era in 
particular Bond's physical resilience and muscularity signal his heroic status (Dodds 2014; Funnell and Dodds 2015).

Although Dr No is the first and only major Bond villain to directly fit the mad scientist stereotype, the association of villainy with scientists has nonetheless persisted in the Bond films. In A View to a Kill (Glen 1985), Dr Carl Mortner (real name, Hans Glaub), mentor and father figure to the main villain Max Zorin, is a former Nazi concentration camp geneticist who hypothesized that superior intelligence could be artificially created by injecting pregnant women with steroids. Zorin is the result of this wartime experimentation, but in addition to being highly intelligent a side-effect of the drugs that were used is that he is also psychotic. Zorin's psychopathic ambition leads him to plan a double earthquake to flood the area around California's Silicon Valley to kill millions and leave him to dominate the global microchip market. The mad scientist is a henchman to the main villain in this film, acting as a loyal assistant, but the backstory of Mortner means that he is also personally responsible for Zorin's amoral ruthlessness and sadistic cruelty, having purposely bred him as a genetically modified product. Seen in this way, Zorin is a Franksteinian monster created by Mortner's obsessed mad science.

The mad scientist in the Bond films can also be presented as a well-meaning but easily manipulated genius who misguidedly becomes a henchman. In Diamonds Are Forever (Hamilton 1971) Professor Doctor Metz - brilliant enough to have two titles - is a laser specialist who has designed the deadly diamond laser satellite that SPECTRE mastermind Blofeld plans to use to extort money from the United States. Metz is 'a committed idealist to peace' and yet has sided with the villain in the naïve belief that Blofeld shares his goal of universal nuclear disarmament. Metz has been led to believe that his device will be used to threaten major destruction unless the superpowers agree to destroy all their nuclear weapons. 
In contrast to both Dr No and Mortner, Metz is not exactly evil at least in terms of motivation; however, he is prepared to use his invention to threaten harm to achieve his idealistic goal.

Nationality and ethnicity are recognized as important to the signification of villainy in the Bond franchise, and impact on the interpretation of the mad scientist stereotype. As Umberto Eco notes in his structuralist essay on the binary oppositions of characters and values that inform the narratives of the Bond novels, Fleming's villains are invariably nationally and/or ethnically other, in contrast to the relative 'purity' of James Bond's Britishness (2009: 40-45). Although the depiction of villainy in the Bond films differs somewhat from the novels, nationality, ethnicity and international politics remain apparent and play a role in the depiction and casting of characters. When historian Jeremy Black considers the association between ethnicity and evil in the Bond films he widens the scope beyond the main villains to comment:

Dr Metz, speaks with a Germanic accent, while the two scientists who design Stromberg's submarine tracking system in The Spy Who Loved Me [Gilbert 1977] have Eastern European names and were cast accordingly [...] The sinister doctor in $\mathrm{A}$ View to a Kill is a German. (2001: 209-10)

Other characters in the Bond films add to this list of scientists including Mr Ling, the Chinese nuclear scientist in Goldfinger involved in the villain's operation Grand Slam; Dr Kaufman, the German forensic scientist and professional assassin in the employ of media mogul Elliot Carver from Tomorrow Never Dies (Spottiswoode 1997); and Vladamir Popov, a Russian scientist and inventor who works for the villain Gustav Graves in Die Another Day (Tamahori 2002). This association is also evident in the literary and film versions of the Dr No character. In the film, the visible otherness of the mad scientist villain's physical deformity is 
accompanied by his presentation as an ethnic other: at dinner he tells Bond that 'I was the unwanted child of a German missionary and a Chinese girl of a good family', identifying his mixed heritage.

\section{The Bond girl scientist}

To avoid generalizations about women in the Bond films it is first necessary to be clear about the term 'Bond girl'. Lisa Funnell argues that the 'term Bond Girl refers to a particular character type of the Bond film [...] a non-recurring character and lead female protagonist, central to the plot of the film and instrumental to the mission of James Bond' and is defined by 'the strong, intimate and intense relationship she builds with Bond' (2008: 63). The Bond girl label is of course highly problematic because of the importance given to James Bond's (possessive) relationship with the women, rather than any independent or professional identity that they might have. The label Bond girl 'diminishes their narrative capacity and social importance' (Funnell 2018: 12). Over time, though, the Bond franchise has made some adjustments to its politics of representation to negotiate changing gender politics. According to Funnell (Funnell 2018; Funnell 2008), prior to the reworked Bond girl concept of the revisionist Craig era, there have been three distinct phases in the development of the Bond girl, in accordance with broader trends in British and American film and television: the 'English partner' phase in the 1960s films, shifting to an American sidekick in need of rescue in the 1970s and the 1980s films, and more recently an action hero in the 1990s and the early 2000s films.

Each of these three phases of representation includes Bond girl scientist characters brought into contact with James Bond in the course of his assignments. As previously noted, in the first Bond film $\operatorname{Dr}$ No Honey Ryder is introduced as the daughter of a marine biologist when James Bond visits a private island off the coast of Jamaica to investigate the villain. 
During the Roger Moore era two Bond girl scientists represent American interests in the franchise, suggesting an Anglo-American alliance: in Moonraker (Gilbert 1979) Dr Holly Goodhead is a CIA field agent working undercover as a NASA space scientist who becomes Bond's partner to thwart the villain Hugo Drax and in A View to a Kill Stacey Sutton is a geologist working for the State of California. James Chapman comments that compared to earlier Bond films Moonraker in particular provides a 'narratively more significant role for the Bond girl' made possible by Holly Goodhead's portrayal as a scientist:

For the first time in the Bond series, the girl possess a narratively important skill which Bond does not: she is able to pilot the space shuttle that is necessary for them to reach Drax's space station, and, later, to track and destroy the nerve gas globes. (2007: 165)

Later in the series, in the Pierce Brosnan era, Denise Richards portrays Dr Christmas Jones, an American nuclear physicist who helps Bond to complete his mission in The World is not Enough. This casting choice followed Richards' breakthrough role in the 1997 Paul Verhoeven science fiction action film Starship Troopers (Funnell 2008: 77). At the time Jones was also likened visually to Lara Croft from the Tomb Raider (2001-ongoing) action adventure video game series.

These female scientist characters still conform closely to the stereotypical Bond girl image in being young and defined by their obvious sex appeal. When The World is not Enough was released critics said that dressed in hot pants and a vest top, Christmas Jones was not remotely believable as a nuclear scientist (Chapman 2007: 230). ${ }^{1}$ In Moonraker, James Bond is initially comically surprised to find that Dr Goodhead is 'a woman' and her name is clearly overtly sexually suggestive, in the Pussy Galore tradition begun by Fleming. As Bond girls, 
the female scientist characters also conform to the requirement of ending the film as a sexual conquest for James Bond. In Bond and Beyond, Bennett and Woollacott observe that the Bond girl of the 1960s and the 1970s who might have taken her independence or liberation too far is reintegrated into social norms through her sexual encounter with Bond (1987: 39). Her joke of a name aside, Goodhead's otherwise 'progressive' representation in Moonraker as a professional scientist and CIA partner to Bond during the mission is duly adjusted at the end of the film in a final seduction scene that also contains one of the most infamous double entendres of the Moore era (Chapman 2007: 165). Twenty years on, the treatment of Christmas Jones at the end of The World is not Enough is remarkably similar. After they have uncovered and stopped a nuclear plot, Jones becomes another of Bond's sexual conquests. The final scenes provide the long-awaited opportunity for jokes to be delivered by Bond at the expense of her suggestive name, and also a visual joke as an embarrassed M and Q and the rest of the MI6 watch Bond with Christmas Jones using a spy satellite that picks up body heat. In the final scenes in both films Bond is literally on top, suggesting his dominant position.

The emphasis placed on attractiveness and romantic relationships has also received attention in research on the depiction of women scientists in the media. Studies by sociologists Eva Flicker (2003, 2008) and Jocelyn Steinke (2005) examine the representations and roles of female scientist characters in fiction film. Stereotypes and character roles of female scientists are argued to differ significantly from those of the male scientist (Flicker 2008: 245). In general, the characteristics of the mad scientist do not apply to female scientist characters, and historically women have less often appeared in the role of professional scientist on-screen (Flicker 2008: 246). Steinke's (2005) research draws on popular films from 1991 to 2001 to analyse the portrayal of female scientists and engineers for the purpose of understanding how they function as role models for adolescent girls. From an analysis of women scientists in 60 feature films in the longer period from the early 1930s to early 2000 Flicker (2008) concludes 
that some transformations of representation can be observed, but describes seven recurring gender stereotypes of women scientists: 'the old maid', 'the gruff women's libber', 'the naïve expert', 'the evil vamp', 'the daughter or assistant', 'the lonely heroine' and 'the clever, digital beauty'. Flicker also concludes that although there have been transformations in the images of women in film over time, the female scientist in particular is subject to sexualization (2008: 254). 'Woman scientist roles present more of a stereotypical woman's role rather than the profession of the scientist' (Flicker 2008: 254), according to Flicker. This is something that is clearly shown by the Bond girl scientists.

The Bond girl scientists already identified conform to Flicker's female scientist typology. As noted earlier, Honey Ryder in $\mathrm{Dr}$ No shows characteristics of the 'daughter or assistant type'. In particular, her subordinate role and introduction as an object of sexual fantasy plays into this type of female character. Holly Goodhead, Stacey Sutton and Christmas Jones can primarily be described as 'the naïve expert' type of female scientist (Flicker 2003: 312, 2008: 248). The naïve expert is 'a very attractive woman' and, in line with Bond girl conventions, she is both rescued and seduced by the hero (Flicker 2008: 248). In Flicker's words, this type of woman scientist:

supplies the audience with some professional knowledge [...] This woman scientist has a brilliant career, but her naiveté and feminine emotions get her into some difficulty in the films' story line. Only a man's help can get her out of these difficulties. (2003: 312)

In A View to a Kill, Stacey Sutton firmly refuses to accept Zorin's bribe to give up her interest in her late father's oil company, and her knowledge of fault lines provides James Bond with geological expertise. However, she is also depicted as an especially helpless Bond girl who is 
in need of Bond's protection, and is saved by him a number of times. At first glance, and due to the timing of The World is not Enough, Christmas Jones might additionally be expected to display characteristics that Flicker associates with the 'clever, digital beauty', represented by intelligent, confident, competent but highly sexualized female action figures like Lara Croft (2008: 249-51). Christmas Jones initially appears confident in her professional role during her initial encounter with Bond, shortcutting jokes about her name and displaying her scientific knowledge, but emphasis is also placed on her sexuality as she is seen removing her protective overalls to display the revealing shorts and tank top inspired by the outfit worn by Lara Croft. Shortly after this, Jones comes across as naïve when she exposes Bond by blowing his cover as a nuclear scientist (Bergman 2012: 318). Even though her expertise is useful during the mission, Jones spends much of the rest of the film attempting to correct the effects of the unintentional error that she made earlier, and it is Bond who predictably saves the day.

\section{Q}

Academic studies show that the portrayal of scientists in popular culture extends from evil and bad to 'good' and positive (Kirby 2017: 294). In line with this, the final scientist character to consider in the Bond films is the Quartermaster, Q. Q is an ally to James Bond in the franchise, providing him with gadgets and technological expertise, and at times venturing into the field. Similar to Bond, Q is an enduring character who exists across time, having so far appeared in 21 of the 24 franchise films. After being absent from two films, the reintroduction of the Q character in the Craig era is especially significant (Hines 2018b). The term 'new Q' acknowledges the transformation that came with Ben Wishaw's casting in the role of a younger Q character in the Craig era Bond films Skyfall and Spectre. However, before discussing this 
new version of $\mathrm{Q}$, it is important to first examine the $\mathrm{Q}$ of the pre-Craig era Bond films, as portrayed by Desmond Llewellyn in From Russia with Love until his death in 1999.

The Connery era Bond films made Q into an important character (Frayling 2005: 19192). In Frayling's history of the scientist and the cinema, he compares the scene in Goldfinger, where Q introduces Bond to his car to the equivalent passage in Fleming's 1959 novel, in which there is no mention of the character (2005: 191). The deliberately 'inconspicuous' Aston Martin DB3 described in the book, which comes supplied with some valuable but comparatively lowkey specialized extras, in the film has become the spectacular Aston Martin DB5, also emphasized in publicity campaigns for Goldfinger. In the film, Q is used to explain to the audience the car's various modifications that Bond later employs during a car chase sequence at the villain's compound, including the bullet-proof shield, machine guns and ejector seat. However, the scene in Goldfinger also does more to establish the character of Q than previously achieved in From Russia with Love, when his appearance is purely functional to supply Bond with his first high-tech gadget attaché case. In preparation for the scene in Goldfinger, director Guy Hamilton advised Llewellyn that Q should show some antagonism towards Bond because of the careless way he treats the gadgetry (Pfeiffer and Lisa 1995: 210). Resultantly, Q appears rather irritated and impatient with Bond throughout the briefing scene, telling him that 'I never joke about my work, 007'. This became a standard part of the Q character, and the Q-Bond relationship. Following Goldfinger, a typical Bond film has normally contained at least one scene with Q in the role of scientist-inventor.

The depiction of Q in the Bond films of the 1960s, the 1970s, the 1980s and the 1990s provides an important corrective to the appearances of the mad scientists. Specifically, the Q character conforms to another scientist stereotype: the British 'boffin'. Robin Jones (1997) writes about the emergence of the boffin character in post-war British films in the period from 1945 to 1970 . Jones traces the boffin stereotype back to the public image of scientists in films 
about Second World War, when the prestige of scientists and scientific research was high (1997: 31). According to Jones, the boffin character is defined primarily through his occupation, and his difference from those he works with, meaning that although he is a government insider he is also an outsider. The boffin can therefore be a somewhat ambivalent figure characterized by his 'obsession with work, a taste for lecturing' and 'separateness' from others. In general, though, the boffin stereotype casts the scientist as heroic in that he is positioned on the side of Britain (Jones 1997: 40). Jones states that the archetypal film boffin is Barnes Wallis in The Dam Busters (Anderson, 1955), but he considers Q to be a later continuation of this stereotype (1997: 41). Jones observes that Q 'looks out of place everywhere but in his workshop, and seems like an outsider in the harsh world of espionage in the field', whereas James Bond is 'professional [and] fits in anywhere' (1997: 41). Certainly the contrasts set up between Q and Bond in the scenes between them prove significant. Both the association of Q with his workshop, and his trips out to join Bond in the field are worth consideration.

As the Head of Q branch, Q is responsible for running the research and development division of British Intelligence. The first workshop-based scene in Goldfinger establishes Q as a behind-the-scenes hero that Bond is sent to meet with. Q branch features in a number of the other pre-Craig era Bond films, not only at the British headquarters of the Secret Service but also in other countries such as Egypt, Brazil and India. Usually, when James Bond enters Q branch he finds Q and his white-coated technicians hard at work, experimenting with new gadget prototypes. In the workshop setting, Q's characteristic irritation with Bond's casual disregard for his inventions continues to come to the fore: the memorable line "Now pay attention 007 ' is iconic of Q's seriousness and annoyance at Bond's lack of care and attention during his explanations of the gadgets. In the British intelligence building, Q branch is depicted as an underground research facility that is in many ways a caricature of a scientist's secret laboratory. This is well illustrated in For Your Eyes Only (Glen 1981), where there is a clear 
difference between the mise en scène of the administrative offices and Q branch. Upstairs, Bond's briefing by the Minister of Defence and the Chief of Staff Bill Tanner takes place in M's traditional but rather elegant office. Q branch, in comparison, is a utilitarian grey-walled, windowless, low-ceilinged and isolated workspace, presumably hidden from the outer world. The secret basement laboratory has been identified as a characteristic feature of the mad scientist film, representative of the dangers of the mad scientist operating outside of the scientific community (Weingart 2003: 284). However, importantly, as a boffin Q is officially working for the government, meaning his research is sanctioned.

From time to time, even though Q is not himself a field agent, he has joined James Bond out in the field. Fieldwork is a setting in which Q can be made to literally look out of place in comparison to the Bond character, who is the supremely confident hero. An essential part of the Bond fantasy is that James Bond is highly adept at dressing the part and can masquerade in the line of duty, transforming to fit in with different social situations and locations (Hines 2018a: 102). In the Connery era, Q makes trips out in Thunderball (Young 1965) and You Only Live Twice (Gilbert 1967) to deliver Bond his field equipment in hot climates. In both instances it is notable that compared to Bond, Q is dressed less stylishly (if not entirely inappropriately), having ditched the suit that is otherwise his work wear. Whereas Bond's casual outfits in these scenes are well-fitted shirt and trouser combinations, Q looks like a tourist in shorts and (in the case of You Only Live Twice a gaudy Hawaiian) shirt. On occasion, though, Q assists Bond in a more active role in his missions: he engages in surveillance and gives Bond a lift in a hot air balloon at the end of Octopussy (Glen 1983) and takes a leave of absence from his job when Bond becomes a rogue agent in Licence to Kill (Glen 1989) to join him and go undercover, posing as a chauffeur, boat crew member and gardener. However, both times following this departure, $\mathrm{Q}$ is returned to the workshop in the next Bond film to revert to the usual franchise formula. 
During 36 years in the role of Q, Llewellyn appeared alongside five of the official Bond actors to provide an unprecedented and long-lasting connection to the character. However, over time, there are some changes made to $\mathrm{Q}$ as he shifts from being a 'brusque colleague to a fatherly confidante' for Bond (Dodds 2015: 215). In large part, this can be related to the character ageing, with Llewellyn still playing the role into his 70 s and $80 \mathrm{~s}$. It is notable that increasingly, in addition to scientific knowledge and gadgetry, the older Q is used to provide comic relief in scenes uttering some especially cringe-worthy lines inspired by Bond's sexual exploits in the Moore era - the 'I think he's attempting re-entry, sir' line as Bond and Holly Goodhead are caught together at the end of Moonraker is perhaps most unforgettable. The long relationship between Q and James Bond reaches the stage of mutual affection in the Brosnan era. By The World is not Enough Bond even looks concerned when the elderly Q seems to hint that he is about to retire. As Martin Willis observes, the choice of John Cleese to play Q's assistant $\mathrm{R}$ in The World is not Enough and afterwards to replace Llewellyn in the Q role in Die Another Day had the effect of heightening the overtly comic aspects of the scientist character that had already developed (2009: 153). When Craig's Bond rebooted the franchise in Casino Royale, Judy Dench's M provided some continuity from the Brosnan era, but Miss Moneypenny and Q were both left out of the franchise until Skyfall, when the film series celebrated its 50th anniversary.

This legacy and the relationship history between Q and Bond have implications for how the new Q might be understood in the Craig era. Wishaw was 32 at the time of Skyfall's release, and Craig was in his mid-forties. There have been older Bond's in the past, but this is the first time that the Q-Bond age gap is reversed to make Q younger. Casting someone younger than Bond has an impact on the connection between the characters. Previously in the Bond films, the Q-Bond pairing usually worked along the lines of Q taking on a teacherly or a parental role compared to Bond as a misbehaving student (Frayling 2005: 192). The longer Q was played 
by Llewellyn, the more strongly the character came to signify 'wisdom and experience' (Dodds 2015: 215). The introduction of a noticeably younger Q flips this aspect of the relationship dynamic. In particular, the National Gallery meeting scene in Skyfall presents Q as the fresh young newcomer in contrast to Craig's Bond as the experienced 00 field agent. The verbal exchange between them highlights Q's relative youth: 'you still have spots' complains Bond once Q has established his identity as the new Quatermaster. Although Bond asserts that 'youth is no guarantee of innovation', Q has already got the jibe in that in his opinion 'Age is no guarantee of efficiency' either. The new Q has been able to match Bond during this meeting, and the scene (re)establishes the elements of gentle antagonism, playful humour, mutual respect, trust and affection characteristic of the Q-Bond relationship.

In Skyfall and Spectre the new Q still performs much the same role as he did in past Bond films, supporting and assisting the Bond character. The relevance of the old stereotype also persists in that the new Q retains the defining characteristics of the boffin. However, as Haynes observes, in the twenty-first century, older scientist stereotypes have been revised by some new images of scientists (2016: 31-44; 2017: 337-339). Correspondingly, the younger Q has evolved to conform to another recent stereotype: the male 'geek' or nerd scientist. Surveying studies of the popular image of scientists, David A. Kirby similarly concludes:

The prevalence and nature of scientist stereotypes have changed over time. Whereas the mad scientist and powerless pawn might have been the dominant stereotypes for most of the twentieth century, the past twenty-five years have given rise to the hero and the nerd as the dominant stereotypes. (2017: 293) 
The IT boom since the 1980s and the dawn of the Internet in the 1990s gave rise to cyberculture and the increased value afforded to technological knowledge in today's digital world. In response to an era defined by such advances, scholars and media commentators observe the accompanying reappropriation of the labels geek and nerd, shifting from an insult referring to poor social skills to a sign of cultural capital (Bell 2013). Words like nerd and geek have therefore been used and to some extent reclaimed to reflect more positive associations than they did in the past, and the nerd or geek has even become something of a cultural icon (Kakutani 2000). The reimagining of $Q$ as a geek or nerd scientist illustrates this trend. This was signalled visually by the first official publicity image of the new Q in Skyfall: Q is pictured in the foreground in front of his laptop, while James Bond stands in the background with a large wall screen display behind him. Although Bond is looking predictably well dressed but traditional in his signature suit, Q is (re)styled as the epitome of modern, trendy 'geek chic', wearing black, thick-framed glasses and a shirt and tie under a V-necked cardigan, and using a computer.

In the Craig era the old distinction between the home base and the field agent that was central to the Bond formula has to some extent broken down, a development that also has consequences for how Q is depicted. In Skyfall the new Q is rather pointedly not (re)introduced in his workshop, and the Q-Bond relationship established in the National Gallery meeting scene is knowing and playful but also directly acknowledges the importance of Q's skills and expertise in the digital era and the contemporary world of espionage. Sitting side by side in the art gallery looking at a painting of an old warship being tugged away by a small but powerful new steam boat, Q confidently boasts to Bond that he can do more damage with his computer than Bond can do in the field. Although Q's other scenes in Skyfall take place inside MI6's temporary headquarters, he uses technology to directly assist Bond to track, identify and later leave an electronic trail for the villain. ${ }^{2}$ In Spectre, Q is similarly hands-on in his involvement 
in supporting Bond on his rogue mission. It is also significant that $\mathrm{Q}$ is shown to share Bond's mistrust of the changes to national security that threaten the 00 section, represented by $\mathrm{C}$ and the new MI5 building, having intentionally moved to (re)situate Q branch back underground 'away from prying eyes'. Having helped Bond to evade tracking by his own agency, Q arrives in Austria to assist Bond in the field, and Q also plays a part in the film's London-set finale. When Q turns up in Austria it is Bond who is looking out of place at the Hoffler Klinik's juice bar; after that Q outruns SPECTRE agents and uses his techno-scientific skills to analyse a ring that leads him to the organization's existence. Although the new Q's battlefield is typically virtual rather than real-world his contributions are no less important. James Bond remains the action hero and field agent in Skyfall and Spectre, but Q's active involvement is essential to Bond's success, and Q plays a more complementary role in the film.

\section{Conclusion}

The mad scientist and the Bond girl scientist appear a number of times in the Bond films, reflecting that the prevalence of scientist stereotypes changes over time, and the decline of the mad scientist in popular fiction is reflected by the Bond franchise. Although the original screen Bond villain was a mad scientist, the stereotype is afterwards associated with henchmen, and has not yet been present in the Craig era Bond films. Meanwhile, the Bond girl scientist has undergone some transformation across the different eras of the film franchise, although the emphasis remains on the sexualization of the female scientist. Across the different eras, James Bond's relationship with the villain, Bond girl or Q as ally is used to define his image and action hero status. At the time of writing, it is reported that the plot for the as yet untitled Bond 25 will follow James Bond as he returns to active service in order to recover a kidnapped scientist from a villain armed with dangerous new technology (007.com 2019). Currently, the 
question remains how this latest scientist character of Bond 25 might relate to past types, but it has been confirmed that Wishaw will return as Q (Ibid.). As one of the most enduring characters in the Bond franchise, Q has become an important part of the continuity and change of the film formula. In particular, the change to the young Q played by Wishaw is especially marked and reintroduced Q as a computer scientist-inventor. The transformation of Q from boffin to nerd or geek is reflective of wider shifts in the portrayal of scientists in popular culture. In Skyfall and Spectre, the signification of Q's relationship with technology has become essential in a way that it had not previously been. In earlier Bond eras, although Q introduced Bond to his gadgets, the Bond films privileged Bond's instinctive ability to master technology. In the Craig era, however, the new guise of geek lends $Q$ an alternative form of 'technomasculinity' (Bell 2013: 80). Now, Q not only keeps Bond equipped with the right devices, he also uses technology himself. The familiar Bond formula means that the narratives of Skyfall and Spectre cannot challenge the hegemonic masculinity of James Bond, and yet the updated Q-Bond relationship introduces some innovation, and the new Q exhibits characteristics that signal a shift in the depiction of the twenty-first-century scientist readily identifiable as a hero.

\section{References}

007.com. (2019), 'Bond 25 start of production', The Official James Bond 007, 25 April, https://www.007.com/bond-25-start-of-production/. Accessed 26 June 2019.

007.com. (2007), 'Focus of the week Q (Desmond Llewellyn)', The Official James Bond 007, 27 November, http://www.007.com/focus-week-q-desmond-llewelyn/. Accessed 12 February 2019.Anderson, M. (1955), The Dam Busters, UK: Associated British Production Corporation. Apted, M. (1999), The World is not Enough, UK and USA: United Artists Corporation and Danjaq, LLC. 
Bell, D. (2013), 'Geek myths: Technologies, masculinities, globalizations', in J. Hearn, M. Blagojević and K. Harrison (eds), Rethinking Transnational Men: Beyond, Between and Within Nations, Abington: Routledge, pp. 76-90.

Bennett, T. and Woollacott, J. (1987), Bond and Beyond: The Political Career of a Popular Hero, London: Macmillan.

Bergman, K (2012), 'Girls just wanna be smart? The depiction of women scientists in contemporary crime fiction', International Journal of Gender, Science and Technology, 4:3, pp. 313-29.

Black, J. (2001), The Politics of James Bond: From Fleming's Novels to the Big Screen, London: Praeger.

Broccoli, C. and Zec, D. (1998), When the Snow Melts: The Autobiography of Cubby Broccoli, London: Boxtree.

Campbell, M. (2006), Casino Royale, UK and USA: United Artists Corporation and Danjaq, LLC.

Chapman, J. (2007), Licence to Thrill: A Cultural History of the James Bond Films, 2nd ed., London: I. B. Tauris.

Dodds, K. (2007), 'Screening geopolitics: James Bond and the early Cold War films (19621967)', in M. Power and A. Crampton (eds), Cinema and Popular Geo-Politics, Abingdon: Routledge, pp. 72-94.

(2014), 'Shaking and stirring James Bond: Age, gender and the resilient agent in Skyfall (2012)', Journal of Popular Film and Television, 42:3, pp. 116-30. 
(2015), “'It's not for Everyone': James Bond and Miss Moneypenny in Skyfall', in L. Funnell (ed.), For His Eyes Only: The Women of James Bond, London: Wallflower Press, pp. 214-23.

Eco, U. (2009), 'Narrative structures in Fleming', in C. Lindner (ed.), The James Bond Phenomenon: A Critical Reader, 2nd ed., Manchester: Manchester University Press, pp. 34-55.

Fleming, I. (1958), Dr No, London: Jonathan Cape.

Flicker, E. (2003), 'Between brains and breasts: Women scientists in fiction film: On the marginalization and sexualization of scientific competence', Public Understanding of Science, 12:3, pp. 307-18.

(2008), 'Women scientists in mainstream film: Social role models - a contribution to the public understanding of science from the perspective of film sociology', in B. Hüppauf and P. Weingart (eds), Science Images and Popular Images of the Sciences, London: Routledge, pp. 241-56.

Forster, M. (2008), Quantum of Solace, UK and USA: United Artists Corporation and Danjaq, LLC.

Frayling, C. (2005), Mad, Bad and Dangerous? The Scientist and the Cinema, London: Reaktion.

Funnell, L. (2018), 'Reworking the Bond girl concept in the Craig Era', Journal of Popular Film and Television, 46:1, pp. 11-21.

Funnell, L. (2008), 'From English partner to American action hero: The heroic identity and transnational appeal of the Bond Girl', in C. Hart (ed.), Heroines and Heroes: Embodiment, Symbolism, Narratives and Identity, Midrash: Kingswinford, pp. 61-80. 
Funnell, L. and Dodds, K (2015), “The Man with the Midas Touch”: The haptic geographies of James Bond's body', Journal of Popular Film and Television, 43:3, pp. 121-35.

Gilbert, L. (1967), You Only Live Twice, UK and USA: Metro-Goldwyn-Mayer Studios Inc. and Danjaq, LLC.

(1977), The Spy Who Loved Me, UK and USA: Metro-Goldwyn-Mayer Studios Inc. and Danjaq, LLC.

(1979), Moonraker, UK and USA: Metro-Goldwyn-Mayer Studios Inc. and Danjaq, LLC.

Glen, J. (1981), For Your Eyes Only, UK and USA: Metro-Goldwyn-Mayer Studios Inc. and Danjaq, LLC.

(1983), Octopussy, UK and USA: Metro-Goldwyn-Mayer Studios Inc. and Danjaq, LLC.

(1985), A View to a Kill, UK and USA: Metro-Goldwyn-Mayer Studios Inc. and Danjaq, LLC.

(1989), Licence to Kill, UK and USA: Metro-Goldwyn-Mayer Studios Inc. and Danjaq, LLC.

Hamilton, G. (1964), Goldfinger, UK and USA: Metro-Goldwyn-Mayer Studios Inc. and Danjaq, LLC.

Hark, I. R. (2004), 'Crazy like a Prof: Mad Science and the transgressions of the Rational', in M. Pomerance (ed.), Bad: Infamy, Darkness, Evil and Slime, Albany: State University of New York Press, pp. 301-14.

Haynes, R. D. (2017), From Madman to Crime Fighter: The Scientist in Western Culture, Baltimore: Johns Hopkins University Press.

(2016), 'Whatever happened to the 'mad, bad' scientist? Overturning the stereotype', Public Understanding of Science, 25:1, pp.31-44. 
(2003), 'From alchemy to artificial intelligence: stereotypes of the scientist in Western literature', Public Understanding of Science, 12:3, pp.243-53.

(1994), From Faust to Strangelove: Representations of the Scientist in Western Literature, Baltimore: The Johns Hopkins University Press.

Hines, C. (2018a), The Playboy and James Bond: 007, Ian Fleming and Playboy Magazine, Manchester: Manchester University Press.

(2018b), “"Brave New World”: The New Q, masculinity, and the Craig Era bond films', Journal of Popular Film and Television, 46:1, pp. 46-55.

Jones, R. A. (1997), 'The Boffin: A stereotype of scientists in Post-war British films (19451970)', Public Understanding of Science, 6:1, pp. 31-48.

Kakutani, M. (2000), 'When the geeks get snide', The New York Times, June 27, https://archive.nytimes.com/www.nytimes.com/library/tech/00/06/biztech/articles/27 note.html. Accessed 25 February 2019.

Kirby, D. A. (2017), 'The changing popular images of science', in K. H. Jamieson, D. Kahan and D. A. Scheufele (eds), The Oxford Handbook of The Science of Science Communication, New York: Oxford University Press, pp. 291-300.

Kubrick, S. (1964), Dr Strangelove, UK and USA: Hawk Films.

Lang, F. (1927), Metropolis, Germany: UFA.

Lindner, C. (ed.) (2009), The James Bond Phenomenon: A Critical Reader, 2nd ed., Manchester: Manchester University Press.

Mendes, S. (2012), Skyfall, UK and USA: Danjaq, LLC and Metro-Goldwyn-Mayer Studios. (2015), Spectre, UK and USA: Danjaq, LLC and Metro-Goldwyn-Mayer Studios. 
Pansegrau, P. (2008), 'Stereotypes and images of scientists in fiction films', in B. Hüppauf and P. Weingart (eds), Science Images and Popular Images of the Sciences, London: Routledge, pp. 257-66.

Pfeiffer, L. and Lisa, P. (1995), The Incredible World of 007, London: Boxtree.

Roberts, L. (2008), 'Denise Richards voted worst ever Bond girl...but Andress is still simply the best', Mail Online, 30 January, https://www.dailymail.co.uk/tvshowbiz/article511377/Denise-Richards-voted-worst-Bond-girl--Andress-simply-best.html.

Accessed 25 February 2019.

Shelley, M. ([1881] 1985), Frankenstein, London: Penguin.

Spottiswoode, R. (1997), Tomorrow Never Dies, UK and USA: Eighteen Leasing Corp. and Danjaq, LLC.

Steinke, J. (2005), 'Cultural representations of gender and science: Portrayals of female scientists and engineers in popular films', Science Communication, 27:1, pp. 27-63.

Stevenson, R. L. ([1886] 2000), The Strange Case of Dr Jekyll and Mr Hyde, Harmonsworth: Penguin.

Tamahori, L. (2002) Die Another Day, UK and USA: United Artists Corporation and Danjaq, LLC.

Verhoeven, P. (1997), Starship Troopers, USA: Touchstone Pictures.

Weiner, R. G., Whitfield, B. L. and Becker, J. (eds) (2011), James Bond in World and Popular Culture: The Films are Not Enough, 2nd ed., Cambridge: Cambridge Scholars Publishing. 
Weingart, P. (2003), 'Of power maniacs and unethical geniuses: Science and scientists in fiction film', Public Understanding of Science, 12:3, pp. 279-87.

Whale, J. (1931), Frankenstein, USA: Universal Pictures.

Willis, M. (2009), 'Hard-wear: The millennium, technology and Brosnan's Bond', in C. Lindner (ed.), The James Bond Phenomenon: A Critical Reader, 2nd ed., Manchester: Manchester University Press, pp. 169-83.

Young, T. (1962), Dr No, UK and USA: Metro-Goldwyn-Mayer Studios Inc. and Danjaq, LLC. (1963), From Russia with Love, UK and USA: Metro-Goldwyn-Mayer Studios Inc. and Danjaq, LLC (1965), Thunderball, UK and USA: Metro-Goldwyn-Mayer Studios Inc. and Danjaq, LLC.

\section{Contributor details}

Claire Hines is senior lecturer in film and television at Solent University. Her research and publications focus on sexuality, gender, fantasy and James Bond in the contexts of American and British cultures. She is the author of The Playboy and James Bond (Manchester University Press, 2018) and the editor of Fan Phenomena: James Bond (Intellect, 2015), and she has contributed to a number of collections about Bond.

Contact:

Solent University, East Park Terrace, Southampton SO140YN, UK.

E-mail: Claire.hines@solent.ac.uk

https://orcid.org/ https://orcid.org/0000-0002-9130-6325 
Notes

${ }^{1}$ Interestingly, as Christmas Jones Denise Richards is routinely voted one of the worst Bond girls because she is so unconvincing in the role, followed by Tanya Roberts as Stacey Sutton, meaning that these scientist Bond girls in particular do not fare that well in polls (Roberts 2008).

${ }^{2}$ It must be said, however, that in this more active role $\mathrm{Q}$ can make mistakes on occasion: in Skyfall he plugs Silva's laptop into the MI6 network, allowing the villain to hack the system and escape captivity. 